\title{
Telejornais: a ruptura tonal com as expectativas do subgênero
}

\author{
Elizabeth Bastos Duarte 1 \\ bebethb@terra.com.br \\ com a colaboração de Rose Lumertz de Freitas ${ }^{2}$
}

\begin{abstract}
Resumo: Texto que se propõe a examinar o processo de tonalização dos telejornais em seus diferentes formatos, reflete sobre as expectativas tonais desse subgênero televisual e as possibilidades de ruptura com essa expectativa. Por tom, compreende-se um conjunto de traços de conteúdo responsáveis pela definição do ponto de vista a partir do qual um produto televisual quer ser reconhecido, dando a conhecer ao enunciatário como ele deve interagir com o que lhe está sendo ofertado. Algumas das formas como podem ocorrer essa transgressão puderam ser depreendidas a partir da análise de um telejornal em específico, o Jornal SBT Manhã, veiculado entre março/2004 a agosto /2005.
\end{abstract}

Palavras-chave: Telejornais / formatos / tom.

Résumé: texte se propose à examiner le processus de tonalisation des téléjournaux dans ses différents formats, en faisant une réflexion sur les expectatives tonalles de ce sous-genre televisuel et sur les possibilités de rupture avec cette expectative. Pour ton, on comprend un ensemble des traits traces de contenu responsables pour la définition du point de vue à partir duquel un produit televisuel veut être reconnu, donnant a savoir á l'enunciatáire commnet doit interager avec ce qui lui est offert. Quelques formes de comment peut arriver cette rupture peuvenut être appperçues de l'analyse d'un telejournal, specfiquement le 'SBT Manhã'; veiculé entre mars/2004 et août/2005.

Mot-clef: Téléjornaux / formats / ton.

1 Coordenadora da pesquisa Subgêneros televisuais: entre formatos e tons (Bolsa de Produtividade do CNPq). Pós-doutora em Televisão pela Universidade de Paris 3. bebethb@terra.com.br. 2 Bolsista de iniciação científica da pesquisa Televisão: os diferentes percursos discursivos de operação sobre o real, coordenada pela profa. dra. Elizabeth Bastos Duarte; 2003-2007. 
Summary: The text considers to examine the tone-up process of the telejournals in its different formats, reflects on the tonals expectations of this televisual subtype and the possibilities of rupture with this expectation. The word "tone", we understand as a set of traces of content responsible for the definition of the point of view from which its narrative wants to be recognized for, giving to know to the enunciator as it must interact with the product that it is being offered. Some of the forms which this trespass can occur could have been inferred from the analysis of a telejournal in specific, Journal 'SBT Manhã', diffused between March/2004 to August/2005.

Key word: Telejournals / formats / tone.

Resumen: Texto que examina el proceso de tonalización de los telediarios en sus diversos formatos, reflejando con respecto a las expectativas tonales de ese subgénero televisual y las posibilidades de ruptura con esta expectativa. Por tono, se entiende un conjunto de trazos de contenido responsables por la definición del punto de vista a partir del cual un producto televisual quiere ser reconocido, dando a conocer al enunciatário como él debe interaccionar com lo que le está siendo ofrecido. Algunas de las formas como pueden ocurrir esa transgresión pudieron ser deprendidas a partir del análisis de un telediario en específico, el SBT Manhã (SBT Mañana), exibido entre marzo/2004 y agosto/2005.

Palabra-llave: Telejornais / formatos / tono.

\section{1- Das considerações introdutórias}

Sedentos por informações, somos cativos dos telejornais. Afinal, vivemos a incrível experiência de ter o Planeta aos nossos olhos. Basta clicar, apertar alguns poucos botões. Para dar conta de nossa curiosidade, há canais fechados que centram sua programação em noticiários, há também os canais abertos que apresentam vários telejornais diários. Não se pode esquecer que a televisão nasceu sob a metáfora da janela aberta para o mundo e, por mais que lhe custe, não pode se furtar a essa tarefa. 
Mas, a esse desenvolvimento sem precedentes da tecnologia ligada ao universo da informação, a essa explosão de oferta de informação tanto em âmbito nacional como internacional, a essa associação entre informação e mundialização deveria corresponder um aumento de demanda, ou uma renovação dos telejornais em termos de formato. Se não for assim, como garantir a audiência?

Não obstante, para as instâncias de produção dos telejornais, o difícil é renovar, diante dos formatos muitos engessados, que campeiam por aí cuidadosamente cultivados pelas próprias emissoras, e que hoje fazem parte da expectativa dos telespectadores, tão bem familiarizados com a gramática de formas de expressão televisual. O desafio, então, frente a essa seqüência de noticiários previstos na programação, seria fugir da chatice das notícias requentadas e da prisão das bancadas; em outros termos, propor novos formatos, mudar de tom.

Propomo-nos aqui refletir com mais vagar sobre o processo de tonalização dos telejornais, considerando não só as expectativas do telespectador em relação ao subgênero, como, em decorrência dessas, as possibilidades de ruptura com os formatos já consagrados.

\section{2- Do processo de tonalização televisual}

Pode parecer estranho que se introduza, sem qualquer tipo de aviso prévio, o termo tom na análise da produção televisual. Não obstante, não há necessidade de maiores pesquisas para se constatar que essa expressão é freqüentemente empregada pelos estudiosos e pela crítica de televisão, bem como pelos profissionais do mercado de produção televisual. É de se perguntar, isto sim, que conteúdos se lhe imputam.

Parte-se do pressuposto de que a situação comunicativa televisual comporta, para além das ancoragens de tempo, espaço, aspecto e atores, um outro dispositivo sintático-semântico, a que ousamos chamar de tonalização do discurso. Tal dispositivo diz respeito à conferência de um tom ao discurso, isto é, de um ponto de vista a partir do qual sua narrativa quer ser reconhecida. Tal processo, distinto dos de modalização ou de sensibilização passional, cujas presenças podem ser observadas nas três instâncias de geração dos sentidos, não deve com eles ser confundido, tampouco com a força ilocutória ou perlocutória atribuída ao que é enunciado, 
embora se acredite que o dispositivo em exame participe, em nível discursivo, da articulação dessas categorias, pertencentes a diferentes níveis de estruturação dos sentidos e da significação. O processo de tonalização teria por tarefa a atribuição estratégica de um tom principal ao discurso produzido e a sua articulação com outros tons a ele correlacionados.

Assim, o que se denomina tom no discurso televisual seria decorrente de um alargamento do sentido do termo - tal como é empregado por linguagens isoladas, como a música, a cor, ou o verbal -, alargamento esse sustentado pelo deslocamento da percepção inicial e imediata dos traços significantes responsáveis por sua expressão, em direção ao seu conteúdo. Tal deslocamento de percepção para o plano do conteúdo se deve possivelmente à complexidade dos textos televisuais, para cuja expressão concorrem simultaneamente diferentes linguagens, bem como à ampliação do nível de pertinência semiótica que passa, da consideração de figuras, símbolos ou semi-símbolos, ou signos isolados, ao processo comunicativo televisual como um todo, comportando os textos-produto e seus suportes, bem como as práticas e cenas comunicativas.Dessa forma, em textos complexos como os produtos televisuais (em que as linguagens sonoras e visuais se superpõem, sobredeterminadas pelos meios técnicos), a percepção do tom se dá na direção inversa, do conteúdo à expressão, sendo extensiva à totalidade da emissão.

O tom, nesse contexto e âmbito de pertinência semiótica, pode ser definido como a presença de determinados traços do conteúdo da situação comunicativa atualizada por um produto televisual, responsáveis pela definição de um tipo específico de ancoragem, isto é, de ponto de vista, a partir do qual sua narrativa quer ser reconhecida. Isso implica, para além de plano de realidade discursiva e regime de crença com que opera, o fornecimento de outras indicações, que dêem a conhecer ao enunciatário como ele deve interagir com o que lhe está sendo ofertado.

O processo de tonalização, isto é, de conferência de um tom ao discurso televisual é responsabilidade da instância da enunciação, decisão estratégica do(s) enunciador(es). O tom principal inscrito em um texto é determinante, pois em torno dele se organizam outros tons e modos que se sucedem no decorrer de sua discursivização, segundo as regras de tonalidade. Assim, o(s) enunciador(es), como 
sujeito(s) operador(es) de determinadas seleções e combinações, capazes de produzirem as articulações responsáveis pela instauração da significação, definiria(m) (em nível discursivo) o tom principal a ser conferido ao que é enunciado. Essa deliberação, convém ressaltar, não se refere à maneira como o sujeito quer apresentar a si próprio, nem caracterizar o desenvolvimento propriamente dito da ação ou do tema, mas àqueles traços indicadores do tipo e forma de interação que o texto como um todo pretende manter com o interlocutor. É preciso ter presente que, para além de inclinações, tendências ou outras pecularidades, a escolha de um tom em televisão é uma deliberação de caráter estratégico. Mais ainda, essa deliberação sobre o tom, confere-lhe um caráter interpelativo: acertar o tom, ou melhor, sua expressão, implica que ele seja reconhecido e apreciado pelo telespectador. Se isso não ocorrer, todo o processo de conferência fica comprometido - não obtém êxito.

O tom se dirige, necessariamente, ao meio social. Ele supõe um interlocutor virtual ou atual. O interlocutor, na medida em que é capaz de detectar o tom conferido a um produto televisual, torna-se cúmplice do(s) enunciador(es); percebe sua proposição engajante, adere ao convite que lhe é feito pela instância de enunciação. Trata-se de um jogo que, mais do que para fazê-lo refletir ou entreter-se, tem uma intenção estratégica: mantê-lo cativo, jogo esse que é demasiado astucioso para ser verdadeiramente informação ou mero entretenimento.

Como é previsível, a proposição de um tom orienta-se por um feixe de relações representadas pela tentativa de harmonização entre o tema da emissão, o subgênero do programa, o público a que se destina, e o tipo de interação que pretende manter com ele. Sua escolha oscila entre a subjetividade e a objetividade, próprias do enunciador; daí suas possíveis ambigüidades, resultado de um vai-e-vem que implica sua realização. Não é nunca neutra, procurando sempre fazer jus ao conjunto do real que quer dar a conhecer a partir de um ponto de vista singular. Pressupõe movimentos de modulação e gradação: a modulação compreenderia a passagem do tom principal aos a ele correlacionados; a gradação corresponderia ao aumento ou diminuição de ênfase em determinado tom. Os tons podem combinar-se entre si para dar corpo a uma determinada emissão televisual. Assim, as 
marcas tonais devem encaixar-se no sofisticado mecanismo do programa, articulando-se harmonicamente com os outros componentes narrativos e discursivos, com os mecanismos expressivos, com os entornos e práticas sociais.

A produção televisual oscila basicamente entre dois objetivos fundamentais - informar e divertir - que ora são priorizados isoladamente, ora se combinam. Daí por que se acredita que as demais categorias tonais, articulem-se em torno de uma categoria principal - disposição - que abriga os eixos opositivos.

Acredita-se que cada subgênero televisual atualize, enquanto expectativa social ou prática de audiência, um tom ou uma combinatória tonal. As noções de gênero e subgênero, à maneira de Foucault, têm por papel controlar os poderes e perigos do discurso, adonar-se de acontecimentos aleatórios. Correspondem, de certa forma, à manifestação textual dessas formações veiculadas pela mídia televisão, possuindo, dentre as regras que lhe são próprias, certamente, aquelas referentes à agregação de determinados tons ao discurso genérico. Não se pode esquecer de que o tom, certamente, é um dos mecanismos responsáveis pela configuração do poder discursivo. Mas, é de se perguntar o que podem esses tons, em relação ao discurso? Certamente muito! Os discursos televisuais interagem, interpelam o telespectador; eles podem fazê-lo rir ou chorar, dançar ou brincar, pegar em armas e marchar para a guerra ou recolher e bater em retirada. Como então deixá-los fluir à deriva? Não, isso seria bastante temerário. Daí por que a sociedade os controla.

Por exemplo, o tom principal, expectativa de um subgênero como o telejornal, é o de seriedade, pois ele confere efeitos de sentido de verdade, confiabilidade, credibilidade, ao que está sendo noticiado. A esse tom principal, agregam-se tons complementares, tais como formalidade, contração, profundidade, etc.

Por outro lado, no processo de realização de um subgênero televisual, cada formato manifesta sua escolha tonal, expressa por uma determinada combinatória de tons, que passam a identificar a emissão. O tom, como estrutura acionada pelo enunciador, compreende a relação entre o que já está posto, é conhecido e preditível, - e, portanto, da ordem da cultura, da apreciação coletiva, e o que pode variar, sendo da ordem do intersubjetivo. Assim, o tom de cada emissão televisual é composto por 
elementos dados e elementos novos. Envia, obrigatoriamente, a combinatórias tonais pré-existentes, previstas pelo subgênero, mas reserva espaços opcionais para as novas combinatórias que passam, então, a identificá-lo enquanto formato. Com isso se quer dizer que todo subgênero televisual já tem como dado o tom que lhe seria adequado e que cada formato opcionalmente pode acessar novas combinatórias tonais que o distingam do subgênero stricto sensu. Trata-se de uma relação semântica estreita entre o que ditam as normas do subgênero, ponto de partida, dado que o enunciador e o enunciatário conhecem a priori, e o formato, uma vez que, para assumirem suas especificidades, os formatos rompem, fraturam seus tons de origem, substituindo-os, alterando-os, propondo novas combinatórias tonais. Dessa forma, o tom é traço distintivo entre subgêneros e formatos, pois, embora as produções televisuais de um mesmo subgênero apresentem semelhanças tonais, elas operam com determinadas combinações de tons que as distinguem entre si, tornando-se sua marca registrada. Ainda que não sejam sempre absolutamente originais, essas combinatórias atuam como signo de diferenciação com forte potencial fidelizador do público telespectador.

Nessa perspectiva, as diferenças de combinatórias tonais podem distinguir os telejornais em seus distintos formatos, pois cabe ao enunciador acessar essas duas vertentes tonais, selecioná-las ou combiná-las, projetando uma sobre a outra, com a finalidade de conferir ao programa identidade e adequação com o seu entorno. As escolhas do enunciador operam sobre um fundo comum de discursos que compõem o paradigma do subgênero e suas realizações anteriores. Seguidamente, não obstante, o entorno cria condições locais que vão de encontro ao esquema geral. Mas, como existe sempre a possibilidade de ruptura, a escolha do tom, ao mesmo tempo, consiste em um espaço de liberdade do enunciador, que pode ignorar os entornos representados pelas restrições da formação discursiva, do gênero/subgênero.

Cabe ainda ressaltar que o tom se expressa de forma dissipativa nos produtos televisuais, exigindo que se perscrute o texto em busca desses elementos que sustentam sua manifestação. Do ponto de vista discursivo, interfere na configuração dos atores, do tempo, do espaço, bem como na da própria organização narrativa. Em nível textual, o tom se impõe como uma pretensão de conteúdo em 
busca de diferentes traços expressivos que o exteriorizem. Eles não se dão imediatamente a ver: encontram sua forma de expressão em estruturas dissipativas de diferentes níveis, ligando-se a traços como a harmonização de cores, formas e sons, o jogo de câmeras e edição, os registros de língua, o guarda-roupa, o cenário, a encenação. Dessa forma, os tons configuram-se estrategicamente através da articulação de diferentes substâncias e formas de expressão, que servem simultaneamente para veicular outros sentidos.

\section{3-Sobre os telejornais: expectativas quanto ao subgênero}

Desde o início da história da televisão no Brasil, o telejornal é um subgênero com presença e audiência garantida na programação televisiva. Importado do jornalismo radiofônico, a televisão dele se apropriou de forma descarada, adotando inicialmente até mesmo o nome do noticiário mais famoso na época o Repórter Esso. Tal apropriação, não obstante, trouxe, como é natural, implicações na construção de seu texto, que até então se caracterizava como um relato oral de notícias, utilizando como principal recurso retórico a impostação de voz dos apresentadores: fez com que ele passasse a se expressar a partir da articulação entre imagens e sons, entre linguagens visuais e sonoras, sobredeterminadas pelos meios técnicos de produção, circulação e consumo dos produtos televisivos.

Os telejornais são um tipo especial de noticiário: sua substância de conteúdo são informações sobre acontecimentos políticos, sociais, culturais, administrativos e outros, cujo âmbito pode ser local, nacional e mundial, selecionadas como relevantes para a compreensão do cotidiano. Em razão disso, os processos enunciativo e discursivo dos telejornais transformam essas informações em notícia. É a reciprocidade entre a informação e a notícia que confere forma a essas informações, enquadrando os acontecimentos numa organização que resulta na construção da notícia. A seleção das informações a serem veiculadas, bem como as formas de estruturação desse material informativo são opções estratégicas que consideram as lógicas mercadológicas, tecnológicas e discursivas: ao determinar o grau de noticiabilidade dessas informações, ao definir sua adequação ao subgênero, ao inserilas em um formato específico de telejornal, a televisão manifesta também os seus interesses institucionais. Aliás, é nesse sentido que se pode falar da mídia como 
pautando o real: a ela cabe determinar que acontecimentos do mundo natural e exterior merecem ser noticiados, assim como decidir as formas adequadas de os transformar em notícia; aqueles sobre os quais se cala, simplesmente não ganham existência.

Assim, as notícias enquanto produtos discursivos são submetidas à aplicação de um conjunto de regras de produção que inicia pela inserção de um acontecimento na pauta, isto é, pela seleção de uma informação como noticiável. Para que um acontecimento seja alçado ao status de noticiável, dizem os manuais, ele deve responder a certos requisitos, concernentes à novidade, com vistas a criar efeitos de surpresa, de choque; à atualidade, pois as notícias lutam contra o tempo; à credibilidade, na tentativa de produzirem efeitos de verdade, confiabilidade. Ao articularem detalhes, estabelecerem relações lógicas entre causas e conseqüências, as notícias constroem um todo consistente, conferindo sentidos aos acontecimentos, dotando-os de uma organização estruturada e racional. Mais ainda, há todo um tratamento discursivo de requentamento das notícias de um telejornal a outro. Dessa forma, o processo produtivo das notícias envolve uma equipe capacitada e variada de profissionais: alguns são responsáveis pela captação dos acontecimentos do mundo exterior - agências de notícias internacionais e nacionais, correspondentes, repórteres, fotógrafos e cinegrafistas; outros atuam no interior do próprio meio pauteiros, editorialistas, redatores, operadores de edição, etc.

Do ponto de vista semiótico, é preciso ter claro que os telejornais, ao promoverem os acontecimentos enquanto os dizem e mostram, fazem emergir uma verdade que é discursiva e que, portanto, não coincide, obrigatoriamente, com a verdade dos fatos: trata-se de operações discursivas que produzem, isso sim, efeitos de sentido. Por isso, mesmo que a maior potencialidade da televisão seja a realização de transmissão direta, em tempo real e simultâneo ao dos acontecimentos do mundo exterior; mesmo que toda a transmissão contenha em si a possibilidade de imprevisto, está sempre presente, em qualquer um dos produtos televisivos, seu caráter de midiatização. Afinal, o mundo se nos apresenta por todos os sentidos; no texto televisivo, somente algumas dessas propriedades são transpostas para a superfície artificial do vídeo. Além disso, as parcelas de real, tornadas visíveis, não 
correspondem a seleções arbitrárias: é o que fica enquadrado, é o movimento das câmeras, é o trabalho de edição e sonoplastia que determinam o que e como os acontecimentos vão ser mostrados. Nessa perspectiva, está-se frente a uma construção de linguagens: não mais o real, mas uma realidade discursiva. Assim, embora contenham índices do real, do mundo exterior, as notícias convertem-se em construções produtoras de realidades discursivas, histórias que criam história, aspirando a uma visibilidade plena. E são exatamente as notícias aberrantes e/ou surpreendentes, os fait-divers, que tornam mais evidente o caráter discursivo das notícias.

As realidades televisuais apresentadas pelos telejornais são fruto da fragmentação, da parcialidade; são instituídas a partir de diferentes referências; são concebidas e estruturadas como uma sucessão de itens, de forma a satisfazer a curiosidade do telespectador. Trata-se daquilo que, em outro lugar, propusemos chamar de meta-realidade, cujo propósito, em princípio, é a apresentação do mundo exterior. É certo que, ao vincular esse tipo de realidade discursiva, a televisão fica, de certa forma, comprometida com a verdade e fidedignidade dos acontecimentos noticiados, com os atores sociais envolvidos, assumindo um contrato comunicativo pautado até mesmo por legislação específica, que a obriga a buscar fontes confiáveis para dar garantia ao discurso veiculado, a convocar testemunhas dos acontecimentos de forma a conferir credibilidade aos relatos apresentados, pois o regime de crença que se propõe nesse tipo de programa é o de veridicção.Assim, buscando corresponder ao regime de crença proposto, a televisão procura cercar-se de estratégias discursivas e mecanismos expressivos que garantam os efeitos de sentido de verdade, autenticidade, credibilidade de que carece. Dentre essas estratégias, a conferência de um tom de seriedade vem parecendo imprescindível. À seriedade aliam-se outros tons, como formalidade, contração, distanciamento, profundidade, regularidade, entre outros.

Uma vez que a referência dos acontecimentos e imagens que telejornais apresentam é o mundo exterior, a televisão opera, nesse caso, com dois tipos de espaços: os internos, que são os espaços de estúdio, e os externos, próprios das ações do mundo, dos acontecimentos, conectados pelos dispositivos tecnológicos. A 
gravação ao vivo, a transmissão direta, em tempo real e simultâneo ao do acontecimento, marcas distintivas da tevê, sempre funcionaram como estratégias de garantia desse tipo de discurso. Por isso, do ponto de vista de sua expressão, os telejornais estruturam-se de forma a corresponder e sustentar esses traços. Daí toda uma tradição e cuidado que passam pelo cenário, pela escolha dos apresentadores ou âncoras, pela manutenção de posturas e comportamentos. Normalmente, os cenários dos telejornais colocam os apresentadores em um platô, isto é, em um estrado mais alto, sentados em uma bancada, tendo como fundo espécies de mapas de globo terrestre, ou telas e telões. Essa posição de superioridade assinala quem, nesse contexto, detém a informação e consequentemente o poder. O fundo do cenário aponta para o domínio que a emissora e o programa detêm sobre a informação de acontecimentos em nível planetário. Mais ainda, completando esse cenário, muitas vezes, ao redor desse platô central, mas em plano mais abaixo, há uma série de mesas de trabalho com pessoas, todas em movimento, operando computadores, algumas até mesmo caminhando apressadamente de um lado para o outro. Essa complementação do cenário com a redação em plano mais baixo garante os efeitos de atualidade do noticiário. É como se a notícia estivesse chegando quentinha, pronta para entrar no ar, mesmo quando na verdade se tratam das requentadas. Além disso, ao mostrar os seus bastidores, o em-se-fazendo da notícia, e, com isso, suas condições tecnológicas, a emissora promove, para além da emissão, a si própria. O grande número de pessoas que trabalham de certa maneira aponta para consideração e respeito da emissora pelo telespectador: todo aquele contingente está a seu serviço para lhe oferecer a notícia de última hora.

Há também que se reparar na figura e comportamento dos apresentadores, nos quais as emissoras investem, pelo tom de seriedade que podem conferir à emissão. Muitas vezes, a apresentação é feita em dupla, que, em princípio, deve ter uma justificativa, isto é, qualificações que ultrapassem o modismo ou a estética da carinha bonita na tela. Essa seriedade tem como formas de expressão a aparência física, a postura corporal, o penteado, o vestuário, o comportamento contido, a voz pausada, o uso impecável da linguagem verbal por parte desses apresentadores, etc, além de uma história no jornalismo televisual. Essa história, embora não se expresse explicitamente em cada edição, ela se dá a ver na seqüência das emissões, não só pela 
repetição - a presença e comportamento desses apresentadores dia após dia, ano após ano, como pelo comportamento da emissora em relação a eles, prestigiando-os, convidando-os a participarem de outros programas, dotando-os de visibilidade no circuito midiático. Assim, os telespectadores dispõem desse conhecimento. Há, como se pode ver, então, toda uma gama de mecanismos expressivos que imprimem um tom de seriedade ao que é dito ou mostrado. A Globo, por exemplo, vem apostando, ao longo dos anos, até mesmo na velha fórmula de contratar casais de apresentadores. É só pensar no William Bonner e na Fátima Bernardes que de tão impecáveis, comedidos, formais, bem comportados, só fazem confirmar que uma das grandes estratégias de sustentação dessa credibilidade é a conferência de um tom de seriedade. Por isso, parece indubitável que o tem que a sociedade tenha como expectativa quando assiste a um telejornal refira-se à categoria disposição, focalizando sua ênfase na subcategoria seriedade, articulada com as de formalidade, contratação, distanciamento, regularidade e profundidade. A regularidade, por exemplo, ancora-se na repetição dos cenários, apresentadores, número de blocos, estruturação dos blocos, bordões de abertura, passagem de um bloco a outro, e de fechamento, etc.

\section{4- Sobre o Jornal do SBT manhã: a realização de um formato}

De modo geral, o subgênero telejornal, não só no Brasil, como em outros países, realiza-se lançando mão de uns poucos formatos, cujas alterações, como já analisamos em outro lugar, se devem muito mais às relações entre tempo e tom, do que a efetivas rupturas com sua estrutura genérica.

Assim, por exemplo, em um canal fechado como a Globo News, todos os telejornais, apresentados formalmente em bancada, obedecem a uma mesma organização por blocos, sendo que, no primeiro, os apresentadores fazem as chamadas do que vai ser noticiado, iniciando impreterivelmente com as mesmas palavras; nos demais, as notícias são dispostas pela sua ordem de interesse e relevância, com vistas a manter o telespectador cativo; no último, finalizam também com a repetição de uma mesma expressão de despedida. 
Nos canais abertos, vide Rede Globo de Televisão (RGT), são apresentados em torno de quatro telejornais diários, que, com pequenas alterações de formato e troca de apresentadores, exibem as notícias novas e requentam as já veiculadas nas edições anteriores. Nesse sentido, aliás, o Bom dia Brasil talvez seja uma exceção, pelas diferenças do formato adotado que oscila entre a bancada (notícias requentadas do dia anterior e notícias de acontecimentos que, devido ao horário, já ocorreram em outros locais) e a sala de estar (normalmente antecipando os fatos que deverão ser notícia no dia, intercalados com apresentação de quadros das reportagens). Isso não quer dizer que esse telejornal, em algum momento, opere rupturas com o tom principal de seriedade.

Como a RGT, pelo seu domínio em termos de audiência, serve de referência e padrão de qualidade às outras emissoras nacionais, os formatos de telejornais por ela adotados costumam ser imitados ou copiados, se possível com a contratação de ex apresentadores globais.

É, nessa perspectiva, aliás, que o Jornal do SBT Manhã, exibido na programação da emissora de março de 2004 a agosto de 2005, surpreendeu e, por que não, inovou. Apresentado por Analice Nicolau, modelo e atriz, e Cynthia Benini, jornalista e atriz, ambas participantes de um reality show da emissora, Casa dos artistas, o telejornal era exibido às $6 \mathrm{~h}$ da manhã, de segunda a sextas-feiras, com duração de trinta minutos. Havia, além delas, fazendo parte dos participantes fixos, três comentaristas: José Neumanne Pinto, Denise Campo de Toledo e Daniela Freitas, responsáveis, respectivamente, pelos quadros Direto ao assunto, Sobre economia, e Esportes.

Vale ressaltar que as rupturas, operadas pelo noticiário, não diziam respeito especificamente aos aspectos estruturais do formato que, em princípio, obedecia a organização tradicional dos telejornais matinais, bastante semelhante, aliás, ao empregado pelo Bom dia Brasil (RGT); o telejornal organizava-se em quatro blocos fixos, nos quais as duas apresentadoras, oscilavam entre a ocupação de uma bancada vazada, uma sala de estar ou um telão; e seu conteúdo eram notícias construídas a partir de acontecimentos do mundo exterior.

Logo, em que residia a estranheza que o programa causava? 
Acreditamos tratar-se de uma questão de tom. O tom expectativa dos telejornais, como já se referiu, gira em torno de uma tonalidade principal que é a seriedade, articulada com outros tons complementares que variam na dependência do tempo de apresentação do telejornal e dos próprios acontecimentos. E é exatamente com esse tom principal expectativa de subgênero telejornal que o $S B T$ Manhã rompia. Mas, quais elementos sustentavam essa ruptura?

A ruptura tonal do Jornal SBT Manhã sustentava-se na quebra de princípios de três ordens: (1) o das relações temporais entre os acontecimentos do mundo exterior e as notícias sobre eles veiculadas; (2) da ancoragem, isto é, qualificação e credenciamento de quem apresenta as notícias; (3) o do contexto, isto é, o cenário e guarda-roupa adequados para se "falar" de assuntos relevantes

No que concerne ao primeiro ponto, é preciso ressaltar que, diferentemente de outros, o Telejornal SBT Manhã era uma emissão gravada na noite anterior, composta apenas por notícias já apresentadas anteriormente, requentadas artificialmente, bem como por reapresentações de reportagens, também já exibidas. Assim, eram veiculados na, sexta-feira, por exemplo, resultados de partidas de futebol ocorridas na quarta-feira anterior. Ora, qualquer telejornal sério deve se preocupar com o caráter de novidade das notícias apresentadas, o em cima da hora. Devido a isso, existe mesmo todo um processo de requentamento das notícias. Até mesmo em canais como a Globo News, que apresenta noticiários de hora em hora, e, que, portanto, se vê obrigada a repetir informações, ocorre sempre troca dos apresentadores, e maquiagem dos fatos noticiados. Assim, iniciar o dia com um noticiário gravado na noite anterior, fere todos os princípios e normas do subgênero, tão bem cultivados pelo telejornalismo nacional e internacional.

Quanto ao segundo ponto que diz respeito à escolha das apresentadoras, convém lembrar que participar de um reality show pode dar dinheiro e até fama, mas certamente coloca sob suspeição os atores sociais que aceitam participar do jogo, comprometendo sua credibilidade. Depois, tradicionalmente, como já se refereiu, os apresentadores de telejornais são jornalistas, o que não é o caso de Analice Nicolau.

Finalmente, devido à importância da tarefa que desempenham, espera-se que os âncoras saibam vestir-se e comportar-se à altura de sua tarefa: informar a 
população. Saias curtas, pernocas de fora, calcinhas à mostra, acompanhadas de visível ignorância e despreparo, ilustrados por uma série de gafes, não é bem o que se espera de um telejornal sério.

É de se perguntar, porque, se o programa era editado, esses problemas não eram corrigidos? Não bastasse isso, a própria emissora se encarregou deliberadamente de contribuir para essa falta de seriedade generalizada ao optar por um cenário com bancada vazada, que focalizava mais as curvas das apresentadoras do que as notícias veiculadas.

Certamente, o Jornal do SBT Manhã apostou estrategicamente no rompimento com as expectativas tonais do subgênero, para fugir à mesmice; já que não podia fazer frente ao poderoso, qualificado e bem equipado departamento de telejornalismo da Globo, investiu, ao menos temporariamente, em um tom apatifado que beirava a gozação e a pilhéria.

A reação foi imediata: alguns tornaram-se cativos da emissão; a grande maioria, porém, optou pelo formato tradicional. A RedeTv chegou a reagir fazendo, no humorístico Pânico na TV, uma paródia do SBT Manhã, apresentada em 03/07/o3, em que as protagonistas, Sabrina Sato e Tânia Oliveira, de microssaias, cruzavam as pernas, de forma exagerada, mostrando as calcinhas.

Embora, posteriormente, a emissora tenha recuado, voltando a adotar o formato tradicional do subgênero, com a contratação mesmo de uma equipe de exglobais, capitaneada pela Ana Paula Padrão, não se pode deixar de reconhecer essa tentativa de ruptura. Ela, além disso, comprova algumas de nossas pressuposições: a existência de tom principal expectativa dos subgêneros televisuais; a extensividade desse tom ao processo comunicativo que o engendra como um todo; a possibilidade de ruptura com essas expectativas tonais; o caráter interativo do tom; e, finalmente, os diferentes traços de expressão que podem manifestá-lo e suas repercussões sobre o formato adotado, assim o particularizando. 


\section{5- Bibliografia}

BERTIN-MAGHIT et alli. Discours audivisuels et mutations culturelles. Paris: L'Harmattan, 2002.

BEYLOT, Pierre. Quand la télévision parle d'elle même. Paris: L'Harmattan, 2000.

CALABRESE, Omar. La informacion y el espectador: un juego de pasiones. In: Los juegos de la imagen. Bogotá: Instituto Italiano de Cultura, 1995.

CHARAUDEAU, Patrick. Le discours d'information médiatique: la construction du miroir social. Paris: Nathan, 1997.

DICIONÁRIO da TV Globo. Programas de dramaturgia e entretenimento. Projeto Memória das Organizações Globo.. Rio de Janeiro: Zahar, 2003.

DUARTE. Elizabeth Bastos Duarte. Televisão: ensaios metodológicos. Porto Alegre: Sulina, 2004. v.1.

DUARTE, Elizabeth B.; CASTRO, Maria Lília Dias de (orgs.). Televisão: entre o mercado e a academia. Porto Alegre: Sulina, 2006. Col. Estudos sobre o audiovisual. v.4, 312 p.

FECHINE, Yvana. A instauração da temporalidade no telejornal. In: Caderno da Compós XI Encontro da Associação Nacional dos programas de Pós-Graduação em Comunicação. Rio de Janeiro: Eco/UFRJ, 2002.

FONTANILLE, Jacques. Significação e visualidade: exercícios práticos. Porto Alegre: Sulina, 2005.

JOST, François. Comprendre la télévison. Cinéma 128. Paris: Armand Colin, 2005.

JOST, François. Seis lições sobre televisão. Porto Alegre: Sulina, 2004.

JOST, François. La télévision du quotidien: entre réalité et fiction. Bruxelles: De Boeck, 2001.

LAMBERT, Frédéric, org. Figures de l'anonymat: médias et société. Paris: L'Harmattan, 2001.

MACHADO, Arlindo. A televisão levada a sério. São Paulo: SENAC, 2000. 